\title{
An assessment of Ebola-related stigma and its association with informal healthcare utilisation among Ebola survivors in Sierra Leone: a cross-sectional study
}

Peter Bai James ${ }^{1,2^{*}}$ (D) Jonathan Wardle ${ }^{1}$, Amie Steel ${ }^{1}$ and Jon Adams ${ }^{1}$

\begin{abstract}
Background: We examined the magnitude and correlates of Ebola virus disease (EVD)-related stigma among EVD survivors in Sierra Leone since their return to their communities. In addition, we determined whether EVD-related stigma is a predictor of informal health care use among EVD survivors.

Methods: We conducted a cross-sectional study among 358 EVD survivors in five districts across all four geographic regions (Western Area, Northern Province, Eastern Province and Southern Province) of Sierra Leone. Ebola-related stigma was measured by adapting the validated HIV related stigma for people living with HIV/AIDS instrument. We also measured traditional and complementary medicine (T\&CM) use (as a measure of informal healthcare use). Data were analysed using descriptive statistics and regression analysis.

Results: EVD survivors report higher levels of internalised stigma $(0.92 \pm 0.77)$ compared to total enacted stigma $(0.71 \pm 0.61)$. Social isolation $(0.96 \pm 0.88)$ was the highest reported enacted stigma subscale. Ebola survivors who identified as Christians [AOR $=2.51,95 \% \mathrm{Cl}: 1.15-5.49, p=0.021$, who perceived their health to be fair/poor [AOR = 2.58, 95\%Cl: 1.39-4.77. $p=0.003]$ and who reside in the northern region of Sierra Leone $[\mathrm{AOR}=2.80,95 \% \mathrm{Cl}: 1.29$ 6.07, $p=0.009$ ] were more likely to experience internalised stigma. Verbal abuse $[\mathrm{AOR}=1.95,95 \% \mathrm{Cl}: 1.09-3.49, p=$ $0.025]$ and healthcare neglect $[\mathrm{AOR}=2.35,95 \% \mathrm{Cl}: 1.37-4.02, p=0.002]$ were independent predictors of T\&CM use among EVD survivors.

Conclusion: Our findings suggest EVD-related stigma (internalised and enacted) is prevalent among EVD survivors since their return to their communities. Religiosity, perceived health status and region were identified as independent predictors of internalised stigma. Verbal abuse and healthcare neglect predict informal healthcare use. EVD survivorcentred and community-driven anti-stigma programs are needed to promote EVD survivors' recovery and community re-integration.
\end{abstract}

Keywords: Stigma, Ebola, Ebola survivor, Informal health care, Traditional medicine, Sierra Leone

\footnotetext{
* Correspondence: peter.b.james@student.uts.edu.au

${ }^{1}$ Australian Research Centre in Complementary and Integrative Medicine,

Faculty of Health, University of Technology Sydney, Ultimo, Sydney, NSW 2007, Australia

${ }^{2}$ Faculty of Pharmaceutical Sciences, College of Medicine and Allied Health

Sciences, University of Sierra Leone, Freetown, Sierra Leone
}

(c) The Author(s). 2020 Open Access This article is distributed under the terms of the Creative Commons Attribution 4.0 International License (http://creativecommons.org/licenses/by/4.0/), which permits unrestricted use, distribution, and reproduction in any medium, provided you give appropriate credit to the original author(s) and the source, provide a link to the Creative Commons license, and indicate if changes were made. The Creative Commons Public Domain Dedication waiver (http://creativecommons.org/publicdomain/zero/1.0/) applies to the data made available in this article, unless otherwise stated. 


\section{Background}

The 2014-2016 Ebola virus disease (EVD) outbreak in West Africa is considered the largest and unprecedented public health emergency in the history of the disease [1]. As at the 30th March 2016, the morbidity and mortality figures due to EVD were estimated at 28, 646 and 11, 322 respectively [2]. The West African Ebola outbreak also recorded the highest number of survivors, and current estimates put the number of EVD survivors at more than 10,000 [3]. Many EVD survivors are known to be suffering from short and long-term physical symptoms and mental complications as a result of surviving EVD [4-6]. Psychosocial consequences of EVD survivorship can be traumatic, due to the adverse psychological experiences of individuals with EVD had to grapple with during infection, treatment and post-discharge. These adverse experiences includes various forms of psychosocial challenges such as depression, anxiety and grief due to loss of loved ones and stigma [4].

Stigma constitutes negative attitudes and beliefs that discredit an individual or group of individuals leading to prejudice and societal exclusion [7]. Stigma can lead to experiences and feelings of blame, shame, worthlessness, loneliness, isolation, social exclusion and discrimination in accessing social amenities and healthcare services [8, 9]. Socially undesirable manifestations (prejudice and discrimination) expressed against those with the stigmatizing attributes are known as enacted stigma whereas the feeling of shame, guilt or worthlessness experienced as a result of having the stigmatising attribute is referred to as internalised stigma [10]. EVD-related stigma is largely based on community fear that EVD survivors are still contagious [11]. Such fear is profound if EVD survivors experience post-Ebola sequelae $[12,13]$ or are aware that the Ebola virus can be present in certain immune-protective parts of the body after convalescence (for example, the semen, breast milk, ocular (eye) fluid, and spinal column fluid) $[14,15]$. EVD-related stigma has led to EVD survivors being mocked by their communities [16, 17], being evicted from their homes by their property owners [13, 17], losing their former jobs [11] and being divorced by their spouses $[12,13]$. Some EVD survivors have been prevented from visiting public places such as public toilets and have experienced difficulty in trading commodities at their local market due to a community reluctance to touch their items or money $[12,13]$. EVD-related stigma has been reported by EVD survivors and their communities in DR Congo (35\%), Guinea (26\%) and Liberia (3\%) [18-20], and may be more common among female rather than male EVD survivors [12]. Other factors, which have been reported as predictors of EVD-related stigma, are age, level of education, and having accessed medical care [21]. Liberian research also suggests EVD survivors are reported to be more likely to experience stigma compared to their close contacts who were not infected with EVD virus [22] however the degree of EVD-related stigma may decline among survivors over time [21, 23]. In Sierra Leone, stigmatisation is reported in approximately one third of EVD survivors $[24,25]$.

Stigma associated with infectious disease has been linked to poor adherence to conventional treatment and the utilization of informal or non-integrated forms of health care such as traditional and complementary medicine $(\mathrm{T} \& \mathrm{CM})[26,27]$. T\&CM refers to a number of health systems, products and practices considered to be predominantly outside conventional medical practice and the medical curriculum $[28,29]$. In sub-Saharan Africa, an average of $58 \%$ of the general population is estimated to use T\&CM products and $29 \%$ consult T\&CM practitioners [30]. The key reasons for T\&CM use in Africa have been attributed to its low cost, easy accessibility, the alignment between T\&CM philosophy and local cultural and religious values, perceived safety and efficacy, and dissatisfaction with conventional medicine [30]. In Sierra Leone, T\&CM utilisation is common especially among hypertensive, pregnant women, infertile women, and lactating mothers and in the management of malaria and diarrhoea [31-36]. Studies have reported individuals with HIV/AIDS or mental health diagnoses that experience stigma are more likely to access T\&CM services $[37,38]$. This pattern of use is reportedly due to the users' perception of T\&CM as less stigmatizing than conventional medicine, partly justified by the view that these T\&CM approaches are deeply rooted in the local cultural and traditional practices [37, 38]. Among SARS survivors, T\&CM was reported to be useful in overcoming SARS-related stigmas by creating new social support networks and counteracting potential future stigmatization and discrimination [39].

Most studies on stigma among EVD survivors have focussed on its magnitude and nature both immediately following and over a number of years after discharge from an Ebola treatment centre [11-13, 17-21, 23, 25, 40]. Although recent studies have reported the use of informal healthcare services among EVD survivors [41, 42], globally, no study to date has reported whether EVD-related stigma is associated with T\&CM utilisation among EVD survivors. In addition, none of the published studies in Sierra Leone on EVD survivors has explored the sociodemographic and health-related factors associated with EVDrelated stigma. Such associations are important, as they will inform the design and implementation of future antistigma interventions. Therefore, we examined the magnitude and the sociodemographic and health related correlates of enacted and internalised stigma among EVD survivors in Sierra Leone since their return to their communities. In addition, our study determined whether enacted and internalised stigma are possible predictors of 
informal healthcare service utilisation (T\&CM use) among EVD survivors in Sierra Leone.

\section{Methods}

\section{Study design, setting and participants}

We conducted a cross-sectional questionnaire study between January and August 2018 among EVD survivors across all four geographic regions (Western Area, Northern Province, Eastern Province and Southern Province) of Sierra Leone. Participants in this study were adult EVD survivors aged 18 years and older experiencing post-Ebola sequelae. We excluded EVD survivors whose physical and psychological health limited them from providing information, such as those survivors with memory loss, hearing loss, high fever and bleeding or those experiencing acute emotional distress.

\section{Sampling method}

A sample of 351 EVD survivors was determined using a sample size formula for cross-sectional studies $\left(\mathrm{N}={ }^{\mathrm{z} 2} \mathrm{pq} /\right.$ $\mathrm{d}^{2}$ ). We increased our sample to 400 to make up nonresponses. Multistage sampling method was used to recruit participants across the country. Data was collected from the four geographic regions of Sierra Leone (Western Area, Northern province, Southern province and Eastern province). Five districts were purposefully selected to cover all four geographic regions of the country. The location of the five districts in Sierra Leone are shown in Fig. 1. The five districts are western area urban and western area rural districts (both in the Western area), Bo district (Southern province), Kenema district (Eastern province) and Bombali district (Northern province). These five districts were chosen based on the epidemiological profile of the total confirmed Ebola cases and because they are host to the highest number of Ebola survivors in Sierra Leone. We randomly sampled the required number of EVD survivors in all five districts based on proportional representation using the national list of registered Ebola survivors obtained from the Sierra Leone Association of Ebola survivors (SLAES). Survivors who were randomly chosen were invited to participate in the study via telephone.

\section{Measures}

Demographics and health related characteristics

The survey instrument measures EVD demographics such age, sex, marital status, educational status, religious

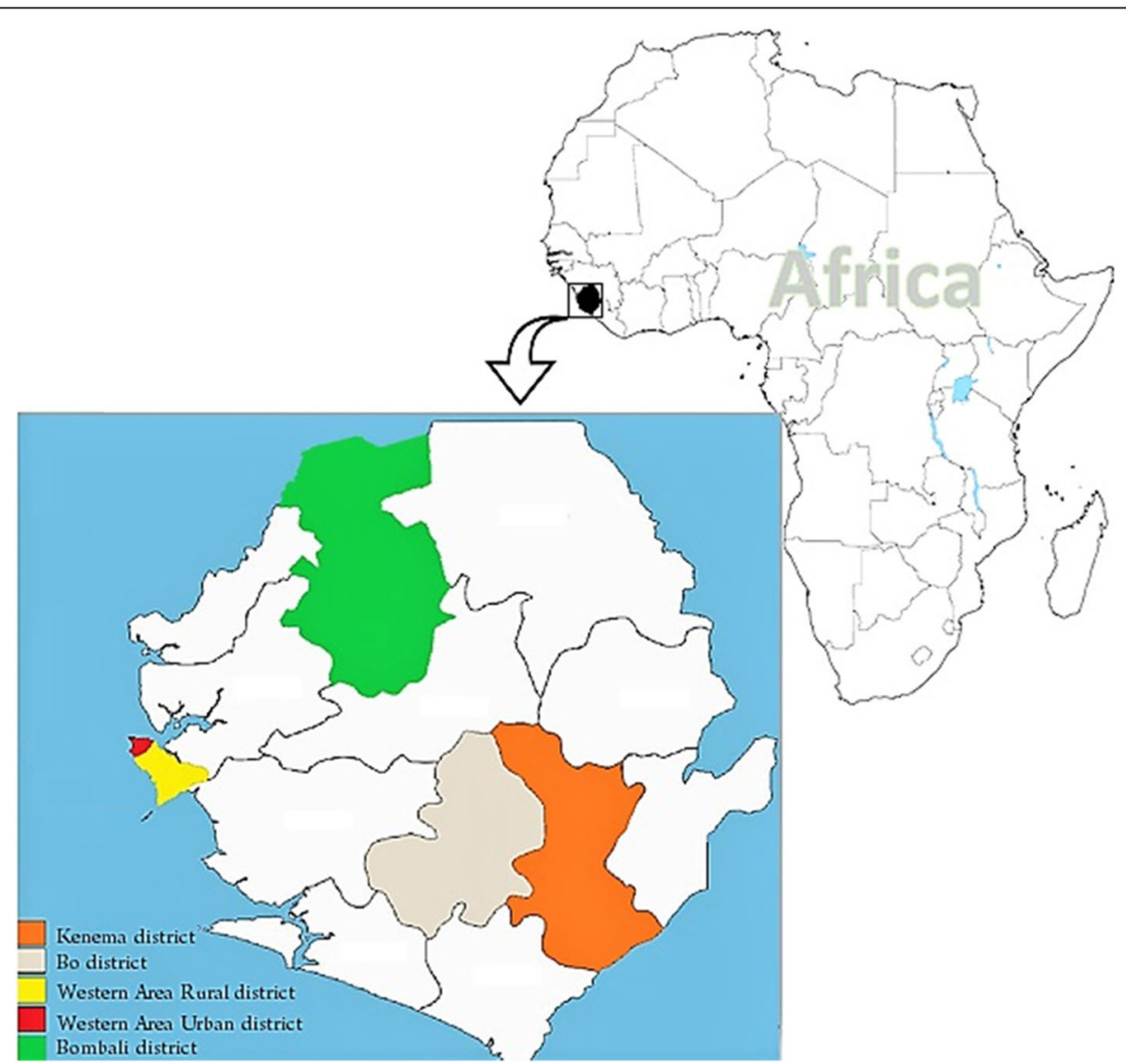

Fig. 1 Locations of the five districts (Western area urban, Western area rural, Bombali, Bo and Kenema) in Sierra Leone. (Source: Map created by the authors) 
affiliation, employment status, financial status, place of residence (urban/rural), geographical region (north, south, east regions and western area) and time (months) since post-discharge. Perceived health status was measured using a five-point Likert scale that ranged from "excellent" to "poor". EVD survivors were asked if they had been diagnosed with any chronic condition prior to being infected with EVD virus.

\section{Ebola-related stigma}

The Ebola-related stigma instrument was adapted from the HIV-related stigma for people living with HIV/AIDS (HASI-P). The HASI-P is a validated 33-item scale that measures stigma among HIV/AIDS patients in the past 3 months [43]. This instrument was validated among HIV/AIDS patients in five African countries: Lesotho, Malawi, South Africa, Swaziland and Tanzania. It consists of the following subscales and this includes verbal abuse (eight items, $\alpha=0.886$ ); healthcare neglect (seven items, $\alpha=0.832$ ); social isolation (five items, $\alpha=0.890$ ); fear of contagion (six items, $\alpha=0.795$ ); and workplace stigma (two items, $\alpha=0.758$ ) all of which measures enacted stigma. The final subscale called negative selfperception (five items, $\alpha=0.906$ ) measures internalised stigma [43]. We decided to use HIV/AIDS related stigma scale (HASI-P) because HIV/AIDS patients share similar psychosocial challenges with EVD survivors in terms of social isolation, fear of contagion and family and community stigma and discrimination [44]. In addition, there is widespread misinformation about HIV/AIDS and EVD. For instance, EVD and HIV/AIDS only affects certain groups of people in society (the poor for EVD and promiscuous adults or homosexuals for HIV/AIDS) and the unfounded community fear of being infected with the virus through means that have not being scientifically proven [44]. To adapt to our setting, the HASI-P was reviewed by two experts in sociology and EVD as well as piloted among 10 EVD survivors. Based on their feedback, we decided to remove the two items that measure workplace stigma since the majority of EVD survivors did not have any paid job before or after EVD. We also removed the statement "At the hospital, I was left in soiled bed" from the healthcare neglect subscale since majority of survivors were not admitted at the clinic/hospital. In addition, the wording of some statements were changed to fit the local EVD survivorship context. Further, we decided to assess stigma experienced by EVD survivors since their discharged from Ebola treatment centre instead of the past 3 months, as was the case when the instrument was validated among HIV/AIDS patients [43]. The final adapted HASI-P instrument used in our study is attached as an Additional file 1.

\section{Use of traditional and complementary medicine}

EVD survivors were asked about their health care utilisation, including whether they have used T\&CM treatment (products and practitioners) since their discharge from the ETC. The common T\&CM modalities considered in our study were informed by studies undertaken previously in Sierra Leone [31-33, 35, 45-47] and across Africa [30]. We considered $\mathrm{T} \& \mathrm{CM}$ in our study to include biological based therapy (herbal medicine and animal extract), spiritual therapy (prayer/faith healing), alternative medicine systems (Chinese herbal medicine, and acupuncture), and physical therapy/body manipulations (massage therapy, traditional bone setting).

\section{Data collection and ethical consideration}

Trained data collectors obtained the relevant information from EVD survivors using self-administered or interviewer-administered (for illiterate participants) formats. The University of Technology Sydney Human Research Ethics Committee (UTS-HREC-ETH17-2080) and the Sierra Leone Ethics and Scientific Review Committee granted ethical clearance. A participant information sheet, explaining the purpose and scope of the study, as well as the option to opt out, was given or read (illiterate) to EVD survivors before seeking their consent to participate. Survivors signing or thumb printing the consent form was interpreted as their willingness to participate. Survivors who signed or thumbed printed (for illiterate participants) the consent form were then given the questionnaire to fill or to be interviewed(for illiterate participants).Three hundred and fifty eight EVD survivors consented and completely filled the questionnaire and were included in the data analysis. We collected our data between May and August 2018 and it was done either at the regional office of EVD survivors or their homes or the village courtyard.

\section{Data analysis}

We used IBM SPSS Statistics version 25 to perform all analyses. Each of the 30 stigma items was assigned a score of 0 to $3(0=$ never, $1=$ once or twice, $2=$ several times and $3=$ most of the time). For each participant, we summed the scores and divided by the number of items to get the mean score for each of the factors/subscales. To obtain the overall total stigma mean score, we summed up the mean scores of each of the factors and divided by 30 . Stigma was analysed as a binary variable (yes/no). Mean stigma score of zero means that none of the items (experiences) in each of the subscales (internalised stigma, verbal abuse, healthcare neglect, fear of contagion and social isolation) occurred since discharged from the ETC. A mean stigma score greater than zero indicated that at least one of the items in each of the subscales occurred once or twice or several times or 
most of the time. As a binary variable, mean score of zero was taken as the absence of stigma and greater than zero was taken present of stigma. We employed chi-square and Fischer exact two tailed tests to determine the association between stigma subscales and sociodemographic and health related variables. We conducted a backward stepwise regressions analysis to establish the most parsimonious model that determines the sociodemographic and health related predictors of internal and enacted stigma. We also used backward stepwise regressions analysis to establish the most parsimonious model that predicts whether internal and enacted stigma is an independent predictor of informal healthcare use (T\&CM use). To determine the independent association between EVD -related stigma and T\&CM use, all of the sociodemographic (age, sex, marital status, religious affiliation, employment status residence etc.) and health related (perceived health status, Duration(years) since discharged from ETC, known chronic disease) variables were taken as potential cofounders and were adjusted for in the regression analysis. Probability less than 0.05 was as statistically significant for all inferential statistical analyses.

\section{Results}

Out of the 400 survivors invited to participate in the study, 377 of them agreed to take part in the study. However, 19 failed to completely fill the questionnaire. Thus, complete data on 358 EVD survivors were analysed. Table 1 gives a summary of EVD survivors' sociodemographic and healthrelated characteristics. More than half $(n=194,54.2 \%)$ of survivors were within the ages of 18-33 years and close to two-thirds $(n=223,62.3 \%)$ were females. Also close to three -fourths $(n=262,73.2 \%)$ of survivors perceived their health to be fair/poor.

\section{Stigma experienced by EVD survivors}

Based on the calculated mean scores, EVD survivors reported higher levels of internalised stigma $(0.92 \pm 0.77)$ compared to enacted stigma $(0.71 \pm 0.61)$. Among the enacted stigma subscale, social isolation $(0.96 \pm 0.88)$ and healthcare neglect $(0.46 \pm 0.53)$ were the highest and least respectively. We categorised stigma scores into (yes /no) as there was little variability in stigma scores. In general, majority of Ebola survivors endorsed at least one item exploring internalised stigma $(n=298,83.2 \%)$ and any of the three subscales measuring enacted stigma $(n=333,93 \%)$. Verbal abuse $(n=276,77.1 \%)$ and fear of contagion $(n=$ $225,62.8 \%$ ) were the highest and least reported enacted stigma subscales respectively (see Table 2 ).

Association between stigma and sociodemographic and health related variables among Ebola survivors

Table 3 summarises the comparison of internalized and enacted stigma with sociodemographic and health related
Table 1 Sociodemographic and health-related characteristics of EVD survivors $(N=358)$

\begin{tabular}{|c|c|c|}
\hline Characteristics & Variables & Total n (\%) \\
\hline \multirow[t]{3}{*}{ Age group } & $18-33$ years & 194(54.2) \\
\hline & $34-49$ years & 134(37.4) \\
\hline & $\geq 50$ years & $30(8.4)$ \\
\hline \multirow[t]{2}{*}{ Sex } & Male & 135(37.7) \\
\hline & female & $223(62.3)$ \\
\hline \multirow[t]{4}{*}{ Educational Status } & Non-formal education & $147(41.1)$ \\
\hline & Primary & $44(12.3)$ \\
\hline & Secondary & $126(35.2)$ \\
\hline & Tertiary & $41(11.5)$ \\
\hline \multirow[t]{2}{*}{ Religious Affiliation } & Christianity & $92(25.7)$ \\
\hline & Islam & $266(74.3)$ \\
\hline \multirow[t]{3}{*}{ Marital Status } & Single & $100(27.9)$ \\
\hline & Married/Cohabitating & $171(47.8)$ \\
\hline & Divorced/Separated/widowed & $87(24.3)$ \\
\hline \multirow[t]{3}{*}{ Financial management } & $\begin{array}{l}\text { It is impossible/ Difficult all } \\
\text { the time }\end{array}$ & $110(30.7)$ \\
\hline & difficult some time & $238(66.5)$ \\
\hline & Not too bad & $10(2.8)$ \\
\hline \multirow[t]{3}{*}{ Monthly income (Leones) } & Less than 500,000 & $252(70.4)$ \\
\hline & 500,000 - 1million & $94(26.3)$ \\
\hline & >1million & $12(3.4)$ \\
\hline \multirow[t]{2}{*}{ Residential Area } & Urban & 219(61.2) \\
\hline & Rural & 139(38.8) \\
\hline \multirow[t]{4}{*}{ Region } & $\begin{array}{l}\text { Northern region } \\
\text { (Bambali district) }\end{array}$ & $120(33.5)$ \\
\hline & Southern region (Bo district) & $55(15.4)$ \\
\hline & Eastern region (Kenema district) & $62(17.3)$ \\
\hline & Western Area & 121(33.8) \\
\hline \multirow{5}{*}{$\begin{array}{l}\text { Employment status } \\
\text { after surviving Ebola }\end{array}$} & Full time & 164(45.8) \\
\hline & Part time & $16(4.5)$ \\
\hline & Casual/Temporal & $19(5.3)$ \\
\hline & Looking for job & $100(27.9)$ \\
\hline & not in paid work force & $59(16.5)$ \\
\hline \multirow{2}{*}{$\begin{array}{l}\text { Current perceived health } \\
\text { status }\end{array}$} & Very good/Good & $96(26.8)$ \\
\hline & Fair/poor & 262(73.2) \\
\hline \multirow{2}{*}{$\begin{array}{l}\text { Duration(years) since } \\
\text { discharged from ETC }\end{array}$} & $\leq 3$ years & $27(7.5)$ \\
\hline & $>3$ years & $331(92.5)$ \\
\hline \multirow[t]{2}{*}{ Known Chronic disease } & Yes & $46(12.8)$ \\
\hline & No & $312(87.2)$ \\
\hline
\end{tabular}

variables among Ebola survivors. Religious affiliation ( $p=$ $0.038)$ and perceived health status $(p=0.004)$ were associated with internalised stigma. None of the sociodemographic and health related variables was associated with 
Table 2 EVD-related stigma scores experienced by EVD survivors according to the adapted HASI-P stigma instrument

\begin{tabular}{llll}
\hline Stigma scales & Mean (SD) & $\begin{array}{l}\text { Mean score = zero (None of the items } \\
\text { in each of scale was endorsed) } \\
\mathrm{n}(\%)\end{array}$ & $\begin{array}{l}\text { Mean score } \geq 0 \text { (at least one of the } \\
\text { items in each scale was endorsed) } \\
\mathrm{n}(\%)\end{array}$ \\
\hline Internalized stigma (negative self-perception subscale) & $0.92(0.77)$ & $60(16.8)$ & $298(83.2)$ \\
Total enacted stigma (remaining four subscales) & $0.71(0.61)$ & $25(7.0)$ & $333(93)$ \\
Verbal abuse & $0.72(0.76)$ & $82(22.9)$ & $276(77.1)$ \\
Healthcare neglect & $0.46(0.53)$ & $105(29.3)$ & $253(70.7)$ \\
Social isolation & $0.96(0.88)$ & $92(25.7)$ & $266(74.3)$ \\
Fear of contagion & $0.72(0.84)$ & $133(37.2)$ & $225(62.8)$ \\
\hline
\end{tabular}

enacted stigma. After adjusting for possible cofounders through regression analysis, Ebola survivors who were Christians $[\mathrm{AOR}=2.51,95 \% \mathrm{CI}: 1.15-5.49, p=0.021$ ], who perceived their health to fair/poor were $[\mathrm{AOR}=2.58$, 95\% CI: $1.39-4.77 . p=0.003$ ] and who reside in the northern region of Sierra Leone $[\mathrm{AOR}=2.80,95 \% \mathrm{CI}$ : $1.29-6.07$, $p=0.009]$ were more likely to experience internalised stigma (see Table 4). No sociodemographic and health related variables predicted total enacted stigma. Table 5 summarizes the independent association between the individual subscales of the enacted stigma and sociodemographic and health related variables. Ebola survivors who reside in the urban area were more likely $[\mathrm{AOR}=2.7$, 95\%CI: $1.57-4.66, p<0.001]$ and those who live in the Northern Region of Sierra Leone were less likely [AOR = 0.37, 95\%CI: $0.20-0.69 p=0.002$ ] to experience verbal abuse. Survivors residing in the Northern Region compared to those in the Western Area were more likely [AOR $=2.03,95 \% \mathrm{CI}: 1.13-3.64, p=0.018]$ to experience healthcare neglect. EVD survivors residing in the Southern [AOR $=3.11,95 \% \mathrm{CI}: 1.41-6.83, p=0.005]$ and eastern [AOR $=2.44,95 \% \mathrm{CI}: 1.19-5.03, p=0.015]$ regions were more likely to be stigmatised due to fear of contagion than those in the Western area. In addition, EVD survivors in the Eastern region were more likely $[\mathrm{AOR}=3.06,95 \% \mathrm{CI}$ : $1.34-7.02, p=0.008]$ to be socially isolated than those in the western area. Unemployed EVD survivors were more likely $[\mathrm{AOR}=2.13,95 \% \mathrm{CI}: 1.26-3.6, p=0.005]$ to be socially isolated than their employed counterparts.

\section{Association between T\&CM use and internalised and enacted stigma}

Table 6 presents the independent association between $\mathrm{T} \& \mathrm{CM}$ use and internalised and enacted stigma using backwards stepwise binary logistic regression. EVD survivors who experienced enacted stigma were [AOR = 4.58, 95\%CI: 1.51-13.83, $p=0.007]$ more likely to use T\&CM. Further analysis of the subscales of the enacted stigma revealed that verbal abuse $[A O R=1.95,95 \% \mathrm{CI}$ : $1.09-3.49, p=0.025\}$ and healthcare neglect [AOR = 2.35, 95\% CI: $1.37-4.02, p=0.002]$ were independent predictors of T\&CM use among the EVD survivors.
Internalised stigma was not found to be a predictor of T\&CM use $[\mathrm{AOR}=1.93,95 \% \mathrm{CI}: 0.99-3.75, p=0.054]$.

\section{Discussion}

This is the first nationally representative study to determine the prevalence of stigma, its sociodemographic correlates and association with informal and nonintegrated forms of health care such as T\&CM use among EVD survivors in Sierra Leone. One key finding from our study is that EVD survivors report high levels of internalised and enacted stigma since discharge from an Ebola treatment centre which is in line with findings from a longitudinal Liberian study that reported high levels of stigma at baseline but lower levels at subsequent follow-up visits [21, 23]. Our finding also resonates with similar short term and smaller sample size cross-sectional studies in Sierra Leone [24, 25, 48], Liberia [20], Guinea [49], and DR Congo [19, 40],which reported that EVD survivors experience several forms of internalised and enacted stigma. Our result identifies higher occurrence of internalised stigma when compared with the occurrence of total enacted stigma experienced by EVD survivors. Our result contrasts to findings reported in a Liberian longitudinal cohort study that employed a different stigma instrument [23] but is in line with a South African study that employed the same stigma tool to measure stigma among HIV/AIDS patients to that employed in our study [50]. The higher frequency of internalised stigma (negative self-perception) among EVD survivors in our study is a cause for concern and warrants further research attention as it can lead to low self-esteem, low self-efficacy, loss of hope for the future and can interfere with life goal achievement [51]. The findings for EVD studies appear to be similar to some other infectious diseases. For example, similar sequelae have been reported among HIV/AIDS patients in Hong Kong [52] and Uganda [53], in which HIV/ AIDS patients reported to feel less worthy of themselves, guilt, shame and self-blame for having HIV/AIDS.

The common types of enacted stigma faced by EVD survivors in our study were social isolation, verbal abuse and fear of contagion, all of which are congruent with 
Table 3 Comparison of internalized and enacted stigma with sociodemographic and health related variables among Ebola survivors

\begin{tabular}{|c|c|c|c|c|c|c|c|}
\hline \multirow[t]{2}{*}{ Characteristics } & \multirow[t]{2}{*}{ Variables } & \multicolumn{3}{|c|}{ Internalized stigma } & \multicolumn{3}{|c|}{ Enacted stigma } \\
\hline & & Yes n (\%) & No n (\%) & $p$-value & Yes n (\%) & No n (\%) & $p$-value \\
\hline \multirow[t]{3}{*}{ Age group } & 18-33 years & 158(53.0) & $36(60.0)$ & 0.599 & 179(53.8) & $15(60.0)$ & 0.815 \\
\hline & $34-49$ years & 114(38.3) & 20(33.3) & & $125(37.5)$ & $9(36.0)$ & \\
\hline & $\geq 50$ years & $26(8.7)$ & $4(6.7)$ & & $29(8.7)$ & $1(4.0)$ & \\
\hline \multirow[t]{2}{*}{ Sex } & Male & $111(37.2)$ & $24(40.0)$ & 0.688 & 129(38.7) & $6(24.0)$ & 0.143 \\
\hline & female & 187(62.8) & $36(60.0)$ & & 204(61.3) & 19(76.0) & \\
\hline \multirow[t]{4}{*}{ Educational Status } & Non-formal education & $127(42.6)$ & 20(33.3) & 0.551 & $135(40.5)$ & $12(48.0)$ & 0.396 \\
\hline & Primary & $36(12.1)$ & $8(13.3)$ & & $39(11.7)$ & $5(20.0)$ & \\
\hline & Secondary & 103(34.6) & 23(38.3) & & 120(36.0) & $6(24.0)$ & \\
\hline & Tertiary & $32(10.7)$ & $9(15.0)$ & & $39(11.7)$ & $2(8.0)$ & \\
\hline \multirow[t]{2}{*}{ Religious Affiliation } & Christianity & 83(27.9) & $9(15.0)$ & 0.038 & $87(26.1)$ & $5(20.0)$ & 0.499 \\
\hline & Islam & 215(72.1) & $51(85.0)$ & & 246(73.9) & $20(80.0)$ & \\
\hline \multirow[t]{3}{*}{ Marital Status } & Single & 83(27.9) & $17(28.3)$ & 0.676 & $94(28.2)$ & $6(24.0)$ & 0.861 \\
\hline & Married/Cohabitating & $140(47.0)$ & $31(51.7)$ & & 159(47.7) & $12(48.0)$ & \\
\hline & Divorced/Separated/widowed & $75(25.2)$ & 12(20.0) & & $80(24.0)$ & $7(28.0)$ & \\
\hline \multirow[t]{3}{*}{ Financial management } & It is impossible/ Difficult all the time & $91(30.5)$ & 19(31.7) & 0.515 & 102(30.6) & $8(32.0)$ & 0.697 \\
\hline & difficult some time & 197(66.1) & $41(68.3)$ & & $222(66.7)$ & $16(64.0)$ & \\
\hline & Not too bad & 10(3.4) & $0(0.0)$ & & $9(2.7)$ & $1(4.0)$ & \\
\hline \multirow[t]{3}{*}{ Monthly income (Leones) } & Less than 500,000 & 211(70.8) & $41(68.3)$ & & 236(70.9) & $16(64.0)$ & 0.477 \\
\hline & 500,000 - 1million & $76(25.5)$ & 18(30.0) & 0.699 & $85(25.5)$ & $9(26.0)$ & \\
\hline & >1million & $11(3.7)$ & $1(1.7)$ & & $12(3.6)$ & $0(0.0)$ & \\
\hline \multirow[t]{2}{*}{ Residential Area } & Urban & $185(62.1)$ & $34(56.7)$ & 0.432 & $204(61.3)$ & 15(60.0) & 0.901 \\
\hline & Rural & 113(37.9) & $26(43.3)$ & & 129(38.7) & 10(40.0) & \\
\hline \multirow[t]{4}{*}{ Region } & Northern region (Bambali district) & 108(36.2) & $12(20.0)$ & 0.084 & 110(33.0) & 10(40.0) & 0.619 \\
\hline & Southern region (Bo district) & $42(14.1)$ & $13(21.7)$ & & $53(15.9)$ & $2(8.0)$ & \\
\hline & Eastern region (Kenema district) & $51(17.1)$ & $11(18.3)$ & & $59(17.7)$ & $3(12.0)$ & \\
\hline & Western Area & 97(32.6) & $24(40.0)$ & & $111(33.3)$ & 10(40.0) & \\
\hline \multirow[t]{5}{*}{ Employment status after surviving Ebola } & Full time & 134(45.0) & $30(50.0)$ & 0.467 & 149(44.7) & $15(60.0)$ & 0.187 \\
\hline & Part time & $12(4.0)$ & $4(6.7)$ & & $16(4.8)$ & $0(0.0)$ & \\
\hline & Casual/Temporal & $15(5.0)$ & $4(6.7)$ & & $16(4.8)$ & $3(12.0)$ & \\
\hline & Looking for job & $84(28.2)$ & $16(26.7)$ & & $96(28.8)$ & $4(16.0)$ & \\
\hline & not in paid work force & 53(17.8) & $6(10.0)$ & & $56(16.8)$ & $3(12.0)$ & \\
\hline \multirow[t]{2}{*}{ Current perceived health status } & Very good/Good & $71(23.8)$ & $25(41.7)$ & & $88(26.4)$ & $8(32.0)$ & \\
\hline & Fair/poor & $227(76.2)$ & $35(58.3)$ & 0.004 & 245(73.6) & 17(68.0) & 0.544 \\
\hline \multirow[t]{2}{*}{ Duration(years) since discharged from ETC } & $\leq 3$ years & $24(8.1)$ & $3(5.0)$ & 0.414 & $26(7.8)$ & $1(4.0)$ & 0.487 \\
\hline & $>3$ years & 274(91.9) & $57(95.0)$ & & $307(92.2)$ & 24(96.0) & \\
\hline \multirow[t]{2}{*}{ Known Chronic disease } & Yes & $37(12.4)$ & $9(15.0)$ & 0.585 & $43(12.9)$ & $3(12.0)$ & 0.895 \\
\hline & No & $261(87.6)$ & $51(85.0)$ & & $290(87.1)$ & $22(88.0)$ & \\
\hline
\end{tabular}

the common forms of stigma reported by EVD survivors in the wider literature [6]. These findings may be applicable to other emerging infectious disease survivors more generally, as similar forms of stigma from the public and healthcare staff have also been reported among SARS survivors in Hong Kong [54]. Social isolation, verbal abuse and fear of contagion can lead to increased levels of psychological distress, delayed access to medical care, low adherence to medical therapy and reduced quality of life as it has also been reported among HIV/AIDS and mental health patients $[55,56]$. Drawing from lessons learnt from HIV/AIDS-related stigma, several EVD 
Table 4 Adjusted association between demographic and health-related variables and internalized and enacted stigma

\begin{tabular}{|c|c|c|c|c|c|c|c|}
\hline \multirow[b]{2}{*}{ Characteristics } & \multirow[b]{2}{*}{ Variables } & \multicolumn{3}{|c|}{ internalized stigma } & \multicolumn{3}{|c|}{ Enacted stigma } \\
\hline & & $\mathrm{AOR}$ & $95 \% \mathrm{Cl}$ & $p$-value & $\mathrm{AOR}$ & $95 \% \mathrm{Cl}$ & $p$-value \\
\hline \multirow[t]{2}{*}{ Religion } & Islam & 1 & & 0.021 & & & \\
\hline & Christianity & 2.51 & $1.15-5.49$ & & & & \\
\hline \multirow[t]{2}{*}{ Perceived health status } & Very /good & 1 & & 0.003 & & & \\
\hline & Fair/poor & 2.58 & $1.39-4.77$ & & & & \\
\hline \multirow[t]{4}{*}{ Region of country } & Western Area & 1 & & & & & \\
\hline & North region & 2.80 & $1.29-6.07$ & 0.009 & & & \\
\hline & Southern region & 0.85 & $0.38-1.93$ & 0.700 & & & \\
\hline & Eastern region & 1.14 & $0.51-2.56$ & 0.749 & & & \\
\hline \multirow[t]{2}{*}{ Employment status } & Employed & & & & 2.16 & $0.88-5.31$ & 0.093 \\
\hline & Unemployed & & & & & & \\
\hline
\end{tabular}

survivor-centred and community-driven strategies have been suggested that could contribute to EVD survivors' recovery and community re-integration. These include community long-term psychosocial counselling for EVD survivors to enhance their coping skills, community education and social support programs for EVD survivors, recruitment and training of trusted opinion leaders that can spread accurate de-stigmatising messages within communities, minimising social isolation and promoting economic empowerment of EVD survivors and EVD affected communities [44, 57].

The mental health impact of surviving Ebola is enormous, and previous studies have reported that psychological distress, anxiety and depression are widespread among Ebola survivors [4, 6]. Although the impact of Ebola -related stigma on mental illness among Ebola survivors is not well understood, stigma induced psychological distress and anxiety have been found to be associated with adverse mental health outcome among HIV/ AIDS patients [58]. Since HIV/AIDS and Ebola virus disease share similar stigmatizing attributes [44], it is possible that Ebola - related stigma maybe contributing to the mental health complications among Ebola survivors. Thus, it likely that stigma reduction strategies will help reduce the mental health burden among EVD survivors.

EVD survivors in our study who identified as Christians and reside in the northern region were more likely to experience internalised stigma. The reasons for the

Table 5 Adjusted association between demographic and health-related variables and Individual scales of enacted stigma

\begin{tabular}{|c|c|c|c|c|c|c|c|c|c|c|c|c|c|}
\hline \multirow[b]{2}{*}{ Characteristics } & \multirow[b]{2}{*}{ Variables } & \multicolumn{3}{|c|}{ Verbal abuse } & \multicolumn{3}{|c|}{ Healthcare neglect } & \multicolumn{3}{|c|}{ Fear of contagion } & \multicolumn{3}{|c|}{ Social Isolation } \\
\hline & & $\mathrm{AOR}$ & $95 \% \mathrm{Cl}$ & $p$-value & $A O R$ & $95 \% \mathrm{Cl}$ & $p$-value & $\mathrm{AOR}$ & $95 \% \mathrm{Cl}$ & $p$-value & $\mathrm{AOR}$ & $95 \% \mathrm{Cl}$ & $p$-value \\
\hline \multirow[t]{2}{*}{ Sex } & Female & & & & 1 & & & & & & & & \\
\hline & Male & & & & 1.53 & $0.93-2.51$ & 0.094 & & & & & & \\
\hline \multirow[t]{2}{*}{ Religion } & Islam & 1 & & & & & & 1 & & & 1 & & \\
\hline & Christianity & 1.95 & $0.98-3.88$ & 0.056 & & & & 1.62 & $0.94-2.80$ & 0.081 & 1.72 & $0.92-3.19$ & 0.088 \\
\hline \multirow[t]{3}{*}{ Monthly Income(Leones) } & $>1$ million & 1 & & & & & & & & & & & \\
\hline & $<500,00$ & 0.35 & $0.04-2.93$ & 0.330 & & & & & & & & & \\
\hline & 500,00-1million & 0.16 & $0.02-1.43$ & 0.101 & & & & & & & & & \\
\hline \multirow[t]{4}{*}{ Region } & Western Area & 1 & & & 1 & & & 1 & & & 1 & & \\
\hline & North region & 0.37 & $0.20-0.69$ & 0.002 & 2.03 & $1.13-3.64$ & 0.018 & 0.73 & $0.43-1.23$ & 0.231 & 1.15 & $0.65-2.05$ & 0.626 \\
\hline & Southern region & 1.19 & $0.49-2.86$ & 0.701 & 1.43 & $0.69-2.96$ & 0.332 & 3.11 & $1.41-6.83$ & 0.005 & 1.75 & $0.78-3.93$ & 0.174 \\
\hline & Eastern region & 1.61 & $0.65-4.01$ & 0.302 & 0.81 & $0.43-1.53$ & 0.506 & 2.44 & $1.19-5.03$ & 0.015 & 3.06 & $1.34-7.02$ & 0.008 \\
\hline \multirow[t]{2}{*}{ Residence } & Rural & 1 & & & & & & 1 & & & & & \\
\hline & Urban & 2.7 & $1.57-4.66$ & $<0.001$ & & & & 1.50 & $0.94-2.40$ & 0.090 & & & \\
\hline \multirow[t]{2}{*}{ Perceived health status } & Very good/good & & & & & & & 1 & & & & & \\
\hline & Fair/poor & & & & & & & 1.64 & $0.98-2.74$ & 0.060 & & & \\
\hline \multirow[t]{2}{*}{ Employment status } & Employed & & & & & & & & & & 1 & & \\
\hline & Unemployed & & & & & & & & & & 2.13 & $1.26-3.61$ & 0.005 \\
\hline
\end{tabular}


Table 6 Association between T\&CM use and internalized and enacted stigma using backwards stepwise binary logistic regression

\begin{tabular}{|c|c|c|c|c|}
\hline Stigma subscale & & AOR & $95 \% \mathrm{Cl}$ & $p$-value \\
\hline \multirow[t]{2}{*}{ Internalized stigma (negative self-perception subscale) } & No & 1 & & \\
\hline & Yes & 1.93 & $0.99-3.75$ & 0.054 \\
\hline \multirow{2}{*}{$\begin{array}{l}\text { Enacted stigma (Verbal abuse, Healthcare neglect, Social } \\
\text { isolation, Fear of contagion) }\end{array}$} & No & 1 & & \\
\hline & Yes & 4.58 & $1.51-13.83$ & 0.007 \\
\hline \multirow[t]{2}{*}{ Verbal abuse } & No & 1 & & \\
\hline & Yes & 1.95 & $1.09-3.49$ & 0.025 \\
\hline \multirow[t]{2}{*}{ Healthcare neglect } & No & 1 & & \\
\hline & Yes & 2.35 & $1.37-4.02$ & 0.002 \\
\hline \multirow[t]{2}{*}{ Social isolation } & No & 1 & & \\
\hline & Yes & 1.52 & $0.86-2.67$ & 0.146 \\
\hline \multirow[t]{2}{*}{ Fear of contagion } & No & 1 & & \\
\hline & Yes & 1.53 & $0.92-2.55$ & 0.102 \\
\hline
\end{tabular}

high levels of internalised stigma among Christians remain unclear. Going forward, an in-depth ethnography study would be required to explain the high levels of internalised stigma amongst Christians compared to Muslims that was observed in our study. Our study findings also reveal that EVD survivors who perceive their health to be fair/poor are more likely to experience internalised stigma than those who perceive their health to be good. In HIV/AIDS patients, the link between stigma and perceived poor health status is postulated to be because stigma is known to promote poor adherence to treatment, lowers emotional coping and social support networks and reduces access to and usage of health and social services leading to poor health outcomes $[26,38]$. The similarity of our findings suggest that similar concerns may be present for EVD survivors. Further studies are needed to explore the link between internalised stigma and religiosity as well as perceived poor health status among EVD survivors in Sierra Leone. Nonetheless, our results have revealed that religiosity, perceived health status and spatial location are potential predictors of internalised stigma among EVD survivors and, that healthcare provider and social workers should consider these characteristics as possible risk factors for internalised stigma among EVD survivors in Sierra Leone.

Further analysis of the enacted stigma subscales revealed verbal abuse was more likely to occur among EVD survivors residing in urban locations when compared to those living in rural areas. Our finding may be explained by the fact that adherence to local bylaws to prevent stigma and discrimination by the community was more prevalent in rural areas compared to urban areas [59]. Also, previously identified urban-rural community differences in knowledge and perception of, and attitude towards, EVD may also explain our finding [60]. Our study also revealed that EVD survivors who are unemployed were more likely to be socially isolated by their communities than their counterparts who were employed. Such a finding maybe explained given that unemployed EVD survivors are likely to be economically and socially dependent on their families and their communities for their wellbeing and, as such are more likely to experience stigma in the form of isolation from their families and communities compared to employed EVD survivors $[17,61]$.

EVD survivors who experienced healthcare neglect in conventional healthcare settings in our study were more likely to use T\&CM. Our finding is not surprising given that healthcare neglect (negative attitude of healthcare providers, long waiting time or being the last person to be seen by the doctor) leads to patient's dissatisfaction with conventional healthcare - a key driver for T\&CM use in the general and sub-health populations in Africa [30]. Thus, it is important for policy makers and health providers to bear in mind that, like other sub-health populations, EVD survivors will likely seek informal healthcare options if they feel neglected by the conventional health system. At policy level, laws are needed that allow EVD survivors to receive appropriate care in a safe environment without being stigmatised or discriminated. In addition, educational interventions to change the negative attitude towards EVD survivors among health providers are required. However, there were also positive attributes identified for T\&CM use. The high rate of T\&CM use among EVD survivors who experienced enacted stigma (healthcare neglect and verbal abuse) maybe related to the notion that T\&CM may serve as a stigma reduction strategy. For instance, $\mathrm{T} \& \mathrm{CM}$ has been used by patients to resist the terminal understanding of HIV/AIDS and believing that HIV/ AIDS is chronic rather than a terminal illness [27]. Also, HIV/AIDS patients and SARS survivors have used T\&CM practices such as yoga and Tai Chi to create social support groups as people in such settings are less 
likely to act differently to each other since they share similar health status and experiences [27, 39]. Drawing from the experiences of HIV/AIDS patients and SARS survivors in using T\&CM in managing stigma, it is possible that EVD survivors will be using T\&CM not only to address their physical health needs but also to as a coping mechanism against the stigma they are experiencing in their communities and at healthcare facilities. As such, there may be a role for integration of some T\&CM - where appropriate - to help improve conventional health options for EVD survivors. Going forward, welldesigned qualitative research is required to have a deeper understanding of the meanings of $T \& C M$ practice in the everyday lives of EVD survivors.

\section{Limitations}

The following limitations must be considered when interpreting our findings. First, our study may suffer from recall bias as we relied entirely on self-reported data. Second, our study employed a cross-sectional design and, therefore we cannot infer causality between independent and outcomes variables. Third, we adapted the HIV/AIDS-related stigma scale (HASI-P) [43] to measure EVD related stigma among EVD survivors, as there is no detailed or validated tool exist for EVD related stigma. We decided to use HIV/AIDS related stigma scale (HASI-P) because HIV/AIDS share similar characteristics with EVD in terms of social isolation, fear of contagion and family and community stigma and discrimination [44]. Finally, our findings are only applicable to EVD survivors in Sierra Leone and may not be representative of EVD survivors in other neighbouring EVD affected countries. Nevertheless, the national nature of this survey represents one of the most representative samples of stigma in EVD survivors.

\section{Conclusion}

The majority of EVD survivors in Sierra Leone experience both internalised and enacted Ebola-related stigma although internalised stigma was the most common in terms of occurrence. To reduce EVD related stigma, and the impacts of such stigma on EVD survivors' health and wellbeing, EVD outbreak responses should include EVD survivor-centred and community-driven interventions that can help contribute to EVD survivors' recovery and community re-integration. EVD survivors appear drawn to informal and non-integrated care (T\&CM) via both push (i.e. dissatisfaction with conventional care) and pull (i.e. empowerment and social commitments from $\mathrm{T} \& \mathrm{CM}$ ). Future research is needed to have a deeper insight of the meanings of T\&CM practice in the everyday lives of EVD survivors.

\section{Supplementary information}

Supplementary information accompanies this paper at https://doi.org/10. 1186/s12889-020-8279-7.

Additional file 1. Ebola - related stigma Questionnaire.

\section{Abbreviations}

ETC: Ebola treatment centre; EVD: Ebola virus disease; T\&CM: Traditional and complementary medicine

\begin{abstract}
Acknowledgments
We want to extend our thanks and appreciation to the Ebola survivors who consented to take part in this study. We also want to extend our appreciation to the staff of the Sierra Leone Ebola survivors association and staff of the Ebola clinic at 34 Military hospital Wilberforce Freetown as well as all data collectors for their support during data collection.. We also extend our thanks to the Faculty health, University of Technology Sydney to help fund the field work for this study. In addition, we extend our thanks and appreciation to dean and staff of the faculty of Pharmaceutical Sciences, College of Medicine and Allied Health Sciences, University of Sierra Leone. The authors thank Mr. John Alimamy Kabba for helping in creating the map used in this manuscript.
\end{abstract}

\section{Authors' contributions}

PBJ and JW conceived of the study while, PBJ, JW, AS \& JA contributed in designing the study. PBJ analysed the data and wrote the initial draft of the manuscript. JW, AS and JA supervised the process and contributed to the intellectual content of the manuscript. All authors read and approved the final version of the manuscipt.

\section{Funding}

The authors have not declared a specific grant for this research from any funding agency in the public, commercial or not-for-profit sectors.

\section{Availability of data and materials}

Due to confidentiality and privacy concerns, and given the sensitivity surrounding stigma and discrimination among Ebola survivors, our study did not receive approval from the University of Technology Sydney Human Research Ethics Committee and the Sierra Leone Ethics and Scientific Review Committee to publicly share the raw data. Also, Ebola survivors consented to participate in the study on the basis that their data would not be shared with anyone except members of the research team (My Supervisors and I). The raw data informing the findings of this study are stored privately at the University of Technology Sydney data storage platform called Cloudstor. However, upon reasonable request, the anonymised raw data underlying the findings of this study can be made available through the following persons 1. Racheal Laugery, Senior research Ethics officer, University of Technology Sydney Human Research Ethics Committee, University of Technology Sydney, Email: (Racheal.Laugery@uts.edu.au); 2. Edward Foday, Research and Publications Specialist, Sierra Leone Ethics and Scientific Review Committee, Directorate of Policy, Planning and Information, Ministry of Health and Sanitation, Fifth Floor, Youyi Building, East Wing, Freetown, Sierra Leone, Email: efoday@health.gov.sl

\section{Ethics approval and consent to participate}

The University of Technology Sydney Human Research Ethics Committee (UTS-HREC-ETH17-2080) and the Sierra Leone Ethics and Scientific Review Committee granted ethical clearance. Written and oral was obtained from participants.

Consent for publication

Not applicable.

Competing interests

The authors declare that they have no competing interest. 
Received: 6 November 2019 Accepted: 27 January 2020

\section{-}

\section{References}

1. International Ebola Response T, Agua-Agum J, Ariyarajah A, Aylward B, Bawo L, Bilivogui P, Blake IM, Brennan RJ, Cawthorne A, Cleary E, et al. Exposure patterns driving Ebola transmission in West Africa: a retrospective observational study. PLoS Med. 2016;13(11):e1002170.

2. Ebola Situation Report - 30 March 2016 [http://apps.who.int/ebola/currentsituation/ebola-situation-report-30-march-2016 ].

3. WHO: Clinical care for survivors of Ebola virus disease. Interim Guidance. 2016.

4. Lotsch F, Schnyder J, Goorhuis A, Grobusch MP. Neuropsychological longterm sequelae of Ebola virus disease survivors - A systematic review. Travel Med Infect Dis. 2017:18:18-23.

5. Vetter P, Kaiser L, Schibler M, Ciglenecki I, Bausch DG. Sequelae of Ebola virus disease: the emergency within the emergency. Lancet Infect Dis. 2016; 16(6):e82-91.

6. James PB, Wardle J, Steel A, Adams J. Post-Ebola psychosocial experiences and coping mechanisms among Ebola survivors: a systematic review. Tropical Med Int Health. 2019;24(6):671-91.

7. Dovidio JF, Major B, Crocker J. Stigma: introduction and overview. New York, NY, US: Guilford Press; 2000.

8. Frost DM. Social stigma and its consequences for the socially stigmatized. Soc Personal Psychol Compass. 2011;5(11):824-39.

9. Earnshaw VA, Quinn DM. The impact of stigma in healthcare on people living with chronic illnesses. J Health Psychol. 2012;17(2):157-68.

10. Scambler G. Re-framing stigma: felt and enacted stigma and challenges to the sociology of chronic and disabling conditions. Soc Theory Health. 2004; 2(1):29-46.

11. Sow S, Desclaux A, Taverne B, Groupe d'etude P. Ebola in Guinea: experience of stigma among health professional survivors. Bull Soc Pathol Exot. 2016;109(4):309-13.

12. Hewlett BS, Amola RP. Cultural contexts of Ebola in northern Uganda. Emerg Infect Dis. 2003:9:1242-8.

13. Rabelo I, Lee V, Fallah MP, Massaquoi M, Evlampidou I, Crestani R, Decroo T, Van den Bergh R, Severy N. Psychological distress among Ebola survivors discharged from an Ebola treatment unit in Monrovia, Liberia - A Qualitative Study. Front Public Health. 2016:4:142.

14. Deen GF, Knust B, Broutet N, Sesay FR, Formenty P, Ross C, Thorson AE, Massaquoi TA, Marrinan JE, Ervin E. Ebola RNA persistence in semen of Ebola virus disease survivors—preliminary report. In: Mass Medical Soc; 2015.

15. Varkey JB, Shantha JG, Crozier I, Kraft CS, Lyon GM, Mehta AK, Kumar G, Smith JR, Kainulainen MH, Whitmer S. Persistence of Ebola virus in ocular fluid during convalescence. N Engl J Med. 2015;372(25):2423-7.

16. Schwerdtle PM, De Clerck V, Plummer V. Experiences of Ebola survivors: causes of distress and sources of resilience. Prehosp Disaster Med. 2017; 32(3):234-9.

17. Karafillakis E, Jalloh MF, Nuriddin A, Larson HJ, Whitworth J, Lees S, Hageman KM, Sengeh P, Jalloh MB, Bunnell R, et al. 'Once there is life, there is hope' Ebola survivors' experiences, behaviours and attitudes in Sierra Leone, 2015. BMJ Glob Health. 2016;1(3):e000108.

18. Etard JF, Sow MS, Leroy S, Toure A, Taverne B, Keita AK, Msellati P, Magassouba N, Baize S, Raoul H, et al. Multidisciplinary assessment of postEbola sequelae in Guinea (Postebogui): an observational cohort study. Lancet Infect Dis. 2017;17(5):545-52.

19. De Roo A, Ado B, Rose B, Guimard Y, Fonck K, Colebunders R. Survey among survivors of the 1995 Ebola epidemic in Kikwit, Democratic Republic of Congo: their feelings and experiences. Tropical Med Int Health. 1998; 3(11):883-5.

20. de St. Maurice A, Ervin E, Orone R, Choi M, Dokubo EK, Rollin PE, Nichol ST, Williams D, Brown J, Sacra R, et al. Care of Ebola Survivors and Factors Associated With Clinical Sequelae-Monrovia, Liberia. Open Forum Infect Dis. 2018;5(10):ofy239.

21. Kelly JD, Weiser SD, Wilson B, Cooper JB, Glayweon M, Sneller MC, Drew C, Steward WT, Reilly C, Johnson K, et al. Ebola virus disease-related stigma among survivors declined in Liberia over an 18-month, post-outbreak period: an observational cohort study. PLoS Negl Trop Dis. 2019;13(2): e0007185.

22. Hanson J, Decosimo A, Quinn M. Diminished Quality of Life among Women affected by Ebola. J Soc Behav Health Sci. 2016;10(1):11.
23. Overholt L, Wohl DA, Fischer WA II, Westreich D, Tozay S, Reeves E, Pewu K, Adjasso D, Hoover D, Merenbloom C. Stigma and Ebola survivorship in Liberia: results from a longitudinal cohort study. PLoS One. 2018;13(11): e0206595.

24. Guetiya Wadoum RE, Samin A, Mafopa NG, Giovanetti M, Russo G, Turay P, Turay J, Kargbo M, Kanu MT, Kargbo B, et al. Mobile health clinic for the medical management of clinical sequelae experienced by survivors of the 2013-2016 Ebola virus disease outbreak in Sierra Leone, West Africa. Eur J Clin Microbiol Infect Dis. 2017;36(11):2193-200.

25. Hugo M, Declerck H, Fitzpatrick G, Severy N, Gbabai O, Decroo T. Posttraumatic stress reactions in Ebola virus disease survivors in Sierra Leone. Emerg Med (Los Angel). 2015;5(6):1-4.

26. Rueda S, Mitra S, Chen S, Gogolishvili D, Globerman J, Chambers L, Wilson M, Logie CH, Shi Q, Morassaei S, et al. Examining the associations between HIV-related stigma and health outcomes in people living with HIV/AIDS: a series of meta-analyses. BMJ Open. 2016;6(7):e011453.

27. Foote-Ardah CE. The meaning of complementary and alternative medicine practices among people with HIV in the United States: strategies for managing everyday life. Sociology of Health \& IIIness. 2003;25(5):481-500.

28. WHO. WHO traditional medicine strategy: 2014-2023. Geneva: World Health Organization; 2013.

29. Adams J, Andrews G, Barnes J, Broom A, Magin P. Traditional, complementary and integrative medicine: an international reader: Macmillan international higher education; 2012.

30. James PB, Wardle J, Steel A, Adams J. Traditional, complementary and alternative medicine use in sub-Saharan Africa: a systematic review. BMJ Glob Health. 2018;3(5):e000895.

31. James PB, Kamara H, Bah AJ, Steel A, Wardle J. Herbal medicine use among hypertensive patients attending public and private health facilities in Freetown Sierra Leone. Complement Ther Clin Pract. 2018;31:7-15.

32. James PB, Bah AJ, Tommy MS, Wardle J, Steel A. Herbal medicines use during pregnancy in Sierra Leone: an exploratory cross-sectional study. Women and Birth. 2017;31(5):e302-9.

33. James PB, Taidy-Leigh L, Bah AJ, Kanu JS, Kangbai JB, Sevalie S. Prevalence and correlates of herbal medicine use among women seeking Care for Infertility in Freetown, Sierra Leone. Evid Based Complement Alternat Med. 2018;2018:9493807.

34. Diaz T, George AS, Rao SR, Bangura PS, Baimba JB, McMahon SA, Kabano A. Healthcare seeking for diarrhoea, malaria and pneumonia among children in four poor rural districts in Sierra Leone in the context of free health care: results of a cross-sectional survey. BMC Public Health. 2013;13(1):157.

35. Ranasinghe S, Ansumana R, Lamin JM, Bockarie AS, Bangura U, Buanie JA, Stenger DA, Jacobsen KH. Herbs and herbal combinations used to treat suspected malaria in Bo, Sierra Leone. J Ethnopharmacol. 2015;166:200-4.

36. James PB, Kaikai Al, Bah AJ, Steel A, Wardle J. Herbal medicine use during breastfeeding: a cross-sectional study among mothers visiting public health facilities in the Western area of Sierra Leone. BMC Complement Altern Med. 2019;19(1):66.

37. Gearing RE, Schwalbe CS, MacKenzie MJ, Brewer KB, Ibrahim RW, Olimat HS, Al-Makhamreh SS, Mian I, Al-Krenawi A. Adaptation and translation of mental health interventions in middle eastern Arab countries: a systematic review of barriers to and strategies for effective treatment implementation. Int J Soc Psychiatry. 2013;59(7):671-81.

38. Peltzer K, Friend-du Preez N, Ramlagan S, Fomundam H. Use of traditional complementary and alternative medicine for HIV patients in KwaZulu-Natal, South Africa. BMC Public Health. 2008:8(1):255.

39. JYm S. Coping with future epidemics: tai chi practice as an overcoming strategy used by survivors of severe acute respiratory syndrome (SARS) in post-SARS Hong Kong. Health Expect. 2016;19(3):762-72.

40. Kelly JD, Hoff NA, Spencer DA, Musene K, Bramble MS, Mcllwain D, Okitundu D, Porco TC, Rutherford GW, Glymour MM, et al. Neurological, cognitive, and psychological findings among survivors of Ebola virus disease from the 1995 Ebola outbreak in Kikwit, Democratic Republic of Congo: a cross-sectional study. Clin Infect Dis. 2019;68(8):1388-93.

41. James PB, Wardle J, Steel A, Adams J. Pattern of health care utilization and traditional and complementary medicine use among Ebola survivors in Sierra Leone. PLoS One. 2019;14(9):e0223068.

42. James PB, Wardle J, Steel A, Adams J. Utilisation of and attitude towards traditional and complementary medicine among Ebola survivors in Sierra Leone. Medicina (Kaunas). 2019;55(7):387. 
43. Holzemer WL, Uys LR, Chirwa ML, Greeff M, Makoae LN, Kohi TW, Dlamini PS, Stewart AL, Mullan J, Phetlhu RD, et al. Validation of the HIV/AIDS stigma instrument - PLWA (HASI-P). AIDS Care. 2007;19(8):1002-12.

44. Davtyan M, Brown B, Folayan MO. Addressing Ebola-related stigma: lessons learned from HIV/AIDS. Glob Health Action. 2014;7:26058.

45. Bakshi SS, McMahon S, George A, Yumkella F, Bangura P, Kabano A, Diaz T. The role of traditional treatment on health care seeking by caregivers for sick children in Sierra Leone: results of a baseline survey. Acta Trop. 2013; 127(1):46-52.

46. James PB, Bah AJ. Awareness, use, attitude and perceived need for complementary and alternative medicine (CAM) education among undergraduate pharmacy students in Sierra Leone: a descriptive crosssectional survey. BMC Complement Altern Med. 2014;14(1):438.

47. James PB, Bah AJ, Kondorvoh IM. Exploring self-use, attitude and interest to study complementary and alternative medicine (CAM) among final year undergraduate medical, pharmacy and nursing students in Sierra Leone: a comparative study. BMC Complement Altern Med. 2016;16(1):121.

48. Nanyonga M, Saidu J, Ramsay A, Shindo N, Bausch DG. Sequelae of Ebola virus disease, Kenema District, Sierra Leone. Clin Infect Dis. 2016;62(1):125-6.

49. Qureshi Al, Chughtai M, Loua TO, Kolie JP, Camara HFS, Ishfaq MF, N'Dour $C T$, Beavogui K. Study of Ebola virus disease survivors in Guinea. Clin Infect Dis. 2015;61(7):1035-42.

50. Sorsdahl KR, Mall S, Stein DJ, Joska JA. The prevalence and predictors of stigma amongst people living with HIV/AIDS in the Western Province. AIDS Care. 2011;23(6):680-5.

51. Corrigan PW, Rao D. On the self-stigma of mental illness: stages, disclosure, and strategies for change. Can J Psychiatr. 2012;57(8):464-9.

52. Mo PKH, Ng CTY. Stigmatization among people living with HIV in Hong Kong: a qualitative study. Health Expect. 2017;20(5):943-51.

53. Nattabi B, Li J, Thompson SC, Orach CG, Earnest J. Factors associated with perceived stigma among people living with HIV/AIDS in post-conflict northern Uganda. AIDS Educ Prev. 2011;23(3):193-205.

54. JY-m S. The SARS-associated stigma of SARS victims in the post-SARS era of Hong Kong. Qual Health Res. 2008;18(6):729-38.

55. Livingston JD, Boyd JE. Correlates and consequences of internalized stigma for people living with mental illness: a systematic review and meta-analysis. Soc Sci Med. 2010;71(12):2150-61.

56. Turan B, Budhwani H, Fazeli PL, Browning WR, Raper JL, Mugavero MJ, Turan JM. How does stigma affect people living with HIV? The mediating roles of internalized and anticipated HIV stigma in the effects of perceived community stigma on health and psychosocial outcomes. AIDS Behav. 2017;21(1):283-91.

57. Feyissa GT, Lockwood C, Woldie M, Munn Z. Reducing HIV-related stigma and discrimination in healthcare settings: a systematic review of guidelines, tools, standards of practice, best practices, consensus statements and systematic reviews. J Multidiscip Healthc. 2018;11:405-16.

58. Earnshaw VA, Chaudoir SR. Behavior: from conceptualizing to measuring HIV stigma: a review of HIV stigma mechanism measures. AIDS Behav. 2009; 13(6):1160

59. Gray N, Stringer B, Bark G, Heller Perache A, Jephcott F, Broeder R, Kremer R, Jimissa AS. Samba TT: 'when Ebola enters a home, a family, a community': a qualitative study of population perspectives on Ebola control measures in rural and urban areas of Sierra Leone. PLoS Negl Trop Dis. 2018;12(6): e0006461.

60. Jalloh MF, Sengeh P, Monasch R, Jalloh MB, DeLuca N, Dyson M, Golfa S, Sakurai Y, Conteh L, Sesay S, et al. National survey of Ebola-related knowledge, attitudes and practices before the outbreak peak in Sierra Leone: August 2014. BMJ Glob Health. 2017;2(4):e000285.

61. Delamou A, Camara BS, Kolie JP, Guemou AD, Haba NY, Marquez S, Beavogui AH, Delvaux T, Griensven J, van Griensven J. Profile and reintegration experience of Ebola survivors in Guinea: a cross-sectional study. Tropical Med Int Health. 2017;22(3):254-60.

\section{Publisher's Note}

Springer Nature remains neutral with regard to jurisdictional claims in published maps and institutional affiliations.

\section{Ready to submit your research? Choose BMC and benefit from:}

- fast, convenient online submission

- thorough peer review by experienced researchers in your field

- rapid publication on acceptance

- support for research data, including large and complex data types

- gold Open Access which fosters wider collaboration and increased citations

- maximum visibility for your research: over $100 \mathrm{M}$ website views per year

At BMC, research is always in progress.

Learn more biomedcentral.com/submissions 